\title{
Colheita dourada a arranca do capim no gerais do Jalapão (TO)
}

\section{Guilherme Moura Fagundes}

\section{(2) OpenEdition \\ 1 Journals}

Edição electrónica

URL: http://journals.openedition.org/aa/3533

DOI: $10.4000 / a a .3533$

ISSN: 2357-738X

Editora

Programa de Pós-Graduação em Antropologia Social (UnB)

\section{Edição impressa}

Data de publição: 1 junho 2019

Paginação: 319-327

ISSN: 0102-4302

\section{Refêrencia eletrónica}

Guilherme Moura Fagundes, «Colheita dourada a arranca do capim no gerais do Jalapão (TO)»,

Anuário Antropológico [Online], v.44 n. 1 | 2019, posto online no dia 06 julho 2019, consultado o 28 abril 2021. URL: http://journals.openedition.org/aa/3533 ; DOI: https://doi.org/10.4000/aa.3533

\section{(c) $(1)(9)$}

Anuário Antropológico is licensed under a Creative Commons Atribuição-Uso Não-Comercial-Proibição de realização de Obras Derivadas 4.0 International. 


\section{Colheita dourada:}

\section{a arranca do capim no gerais do Jalapão (TO)}

Guilherme Moura Fagundes Antropólogo independente - Brasil

O Jalapão (TO) possui uma terra onde se queimando tudo dá. Embora possa parecer contraintuitivo, esse é o caso do capim-dourado. Como se costuma dizer por aquelas bandas, trata-se de uma planta que "só vem forte mó do fogo". Pela taxonomia vegetal, ele está inserido na família Eriocaulaceae, sendo uma florífera dentre as populares sempre-vivas. Pelos jalapoeiros, entretanto, esta cobiçada planta é tida como um capim. Tal acepção diz muito sobre sua estreita interação com as práticas do manejo bovino, pois a queima das veredas possibilita tanto a promoção do capim-dourado quanto a rebrota do capim agreste que alimenta o gado. A arranca do capim é uma atividade que mobiliza famílias inteiras entre o final da estiagem e o início das chuvas, em busca do material a partir do qual se confeccionam artesanatos de grande importância para a economia jalapoeira. Precisamente, 20 de setembro é a data biopolítica demarcada pelos órgãos ambientais como o início da colheita do capim. Entende-se que, por volta desse período, não apenas as hastes estejam secas e douradas para atrair o olhar dos turistas, mas também as sementes amadurecidas o suficiente para permitir a reprodução do vegetal.

As fotografias que compõem este ensaio foram registradas com câmera Nikon D5300 (lente 18-55mm) e retratam três dias de uma arranca do capim junto a Deni, Iracema, Belarmina e Dieison, na rancharia do brejo da Estiva. Meus anfitriões na cidade de Mateiros (TO) e protagonistas do ensaio são quilombolas e geralistas, como se autodenominam no Jalapão aqueles cuja vida depende do ambiente chamado de gerais. Para além do registro de uma atividade extrativista, a composição estética intenta dar destaque a tonalidades, gestos e posturas que caracterizam as interações com o capim-dourado no gerais do Jalapão.

O ensaio também é parte de minha tese de doutorado em antropologia social, desenvolvida ao longo de onze meses de pesquisa de campo, entre os anos de 2014 e 2016. A pesquisa enfoca os modos de existência do fogo no ambiente de gerais e as transformações técnicas oriundas da nova política de manejo integrado do fogo no Jalapão - envolvendo quilombolas, brigadistas e gestores ambientais da Estação 
Ecológica Serra Geral do Tocantins. Em campo, a etnografia buscou conjugar o engajamento nas práticas de queima com a captação de imagens estáticas e em movimento, com vistas a uma análise praxiológica dos gestos técnicos.

Crédito das imagens: Guilherme Moura Fagundes, Mateiros (TO), 2016.

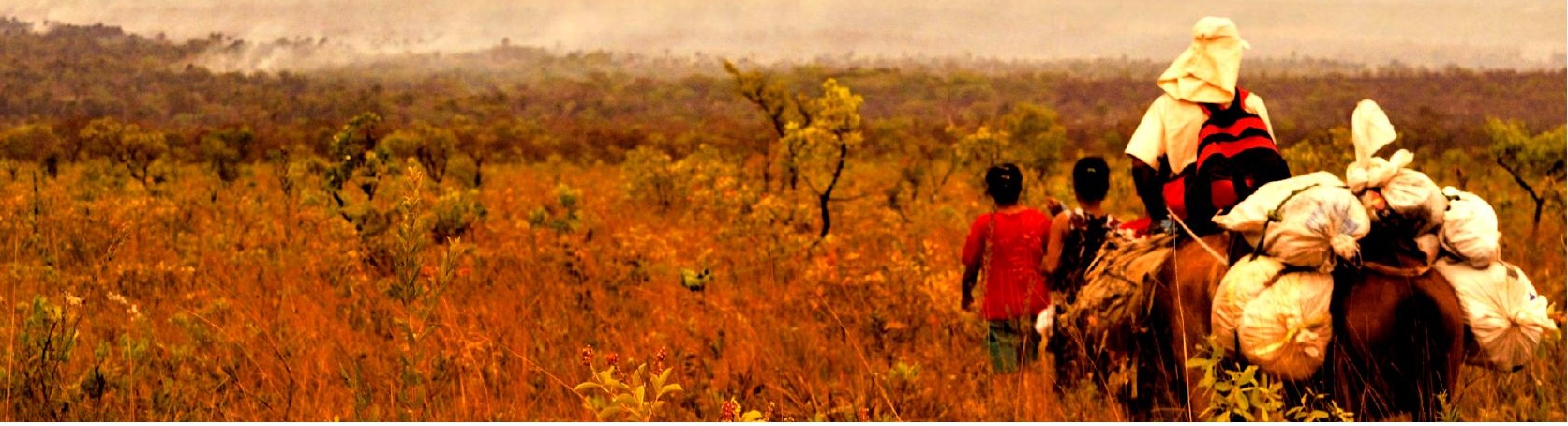

O Jalapão é tido como uma das regiões mais inflamáveis do país. Tal configuração se dá tanto em razão de seus ecossistemas pirofíticos, cuja inevitabilidade de queima é iminente, como ainda pela importância das queimadas no modo de vida geralista. No gerais, o fogo feito para alimentar o gado conflui com o capim-dourado: enquanto o gado se alimenta dos brotos de uma queimada feita no mesmo ano, já o capim-dourado vem forte apenas nas vargens de veredas queimadas no ano precedente. É por isso que a subida para o gerais não deixa de ser um reencontro com lembranças que as famílias possuem acerca das temporalidades das áreas queimadas. Reconhecer o papel do fogo nesta verdadeira trama de natureza e cultura é o primeiro passo para adentrarmos no universo do capim-dourado. 


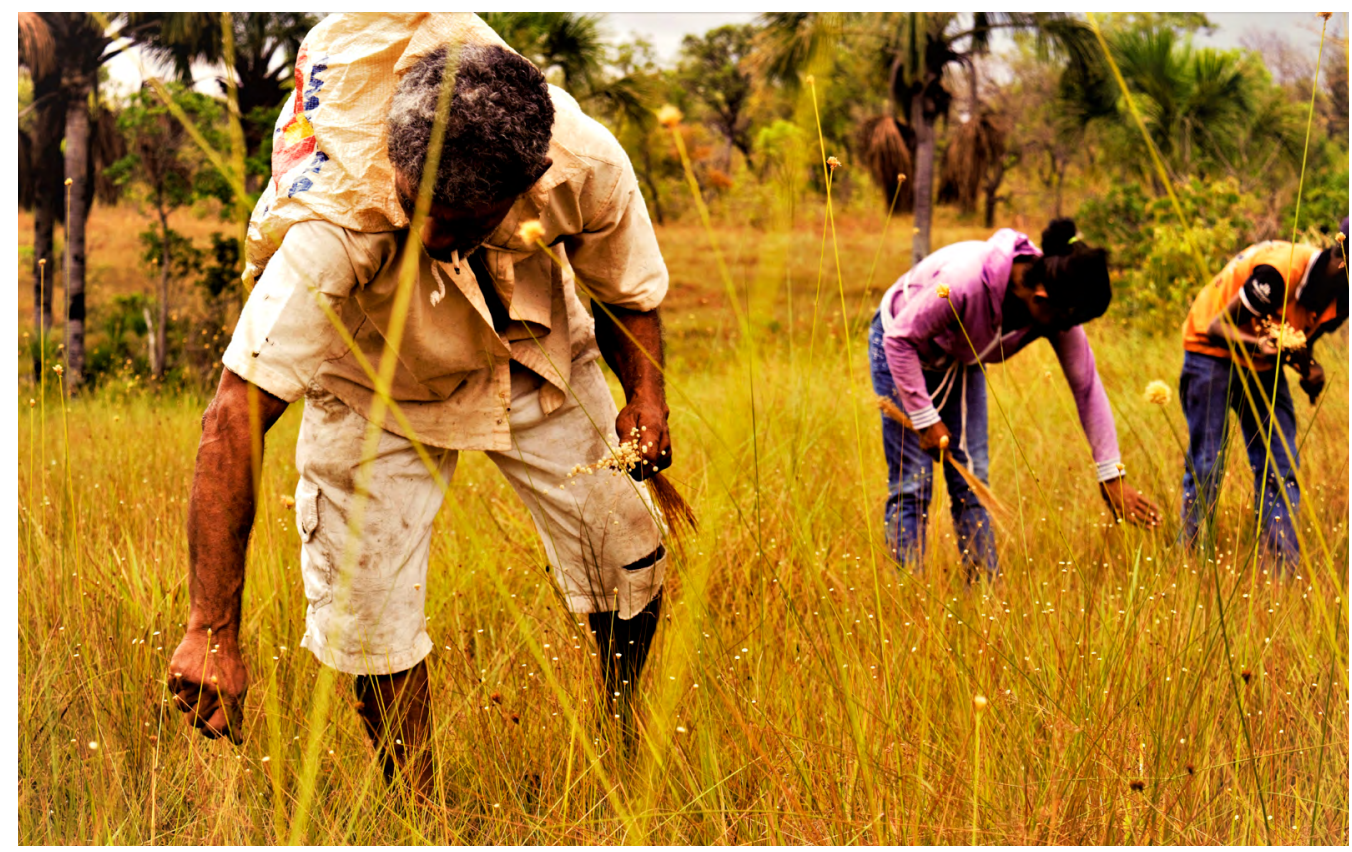

A arranca é uma atividade perambulante, andarilha e sem direção certa, sempre em busca das ilhas de capim. Como dizem, ranca mais quem anda mais. Ao longo do itinerário, a família se separa, cada membro indo numa direção, contornando as veredas em busca dos locais de maior concentração da planta. Enquanto no campo o capim é ajuntado de maneira disforme, a separação dos maços é feita na rancharia. Nestas duas imagens, Deni, Iracema, Belarmina e Dieison se reencontram na vereda da Estiva, após duas horas de coleta.

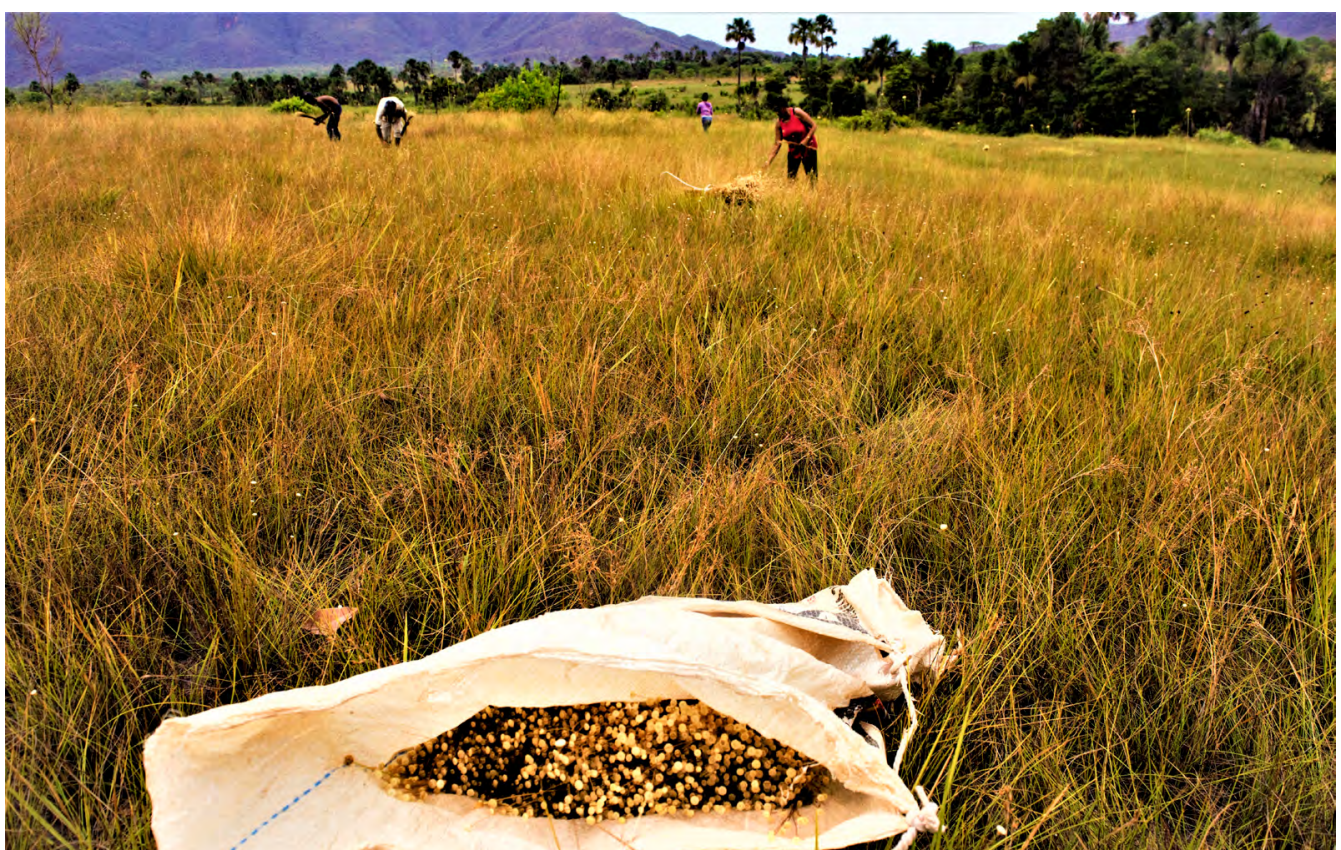



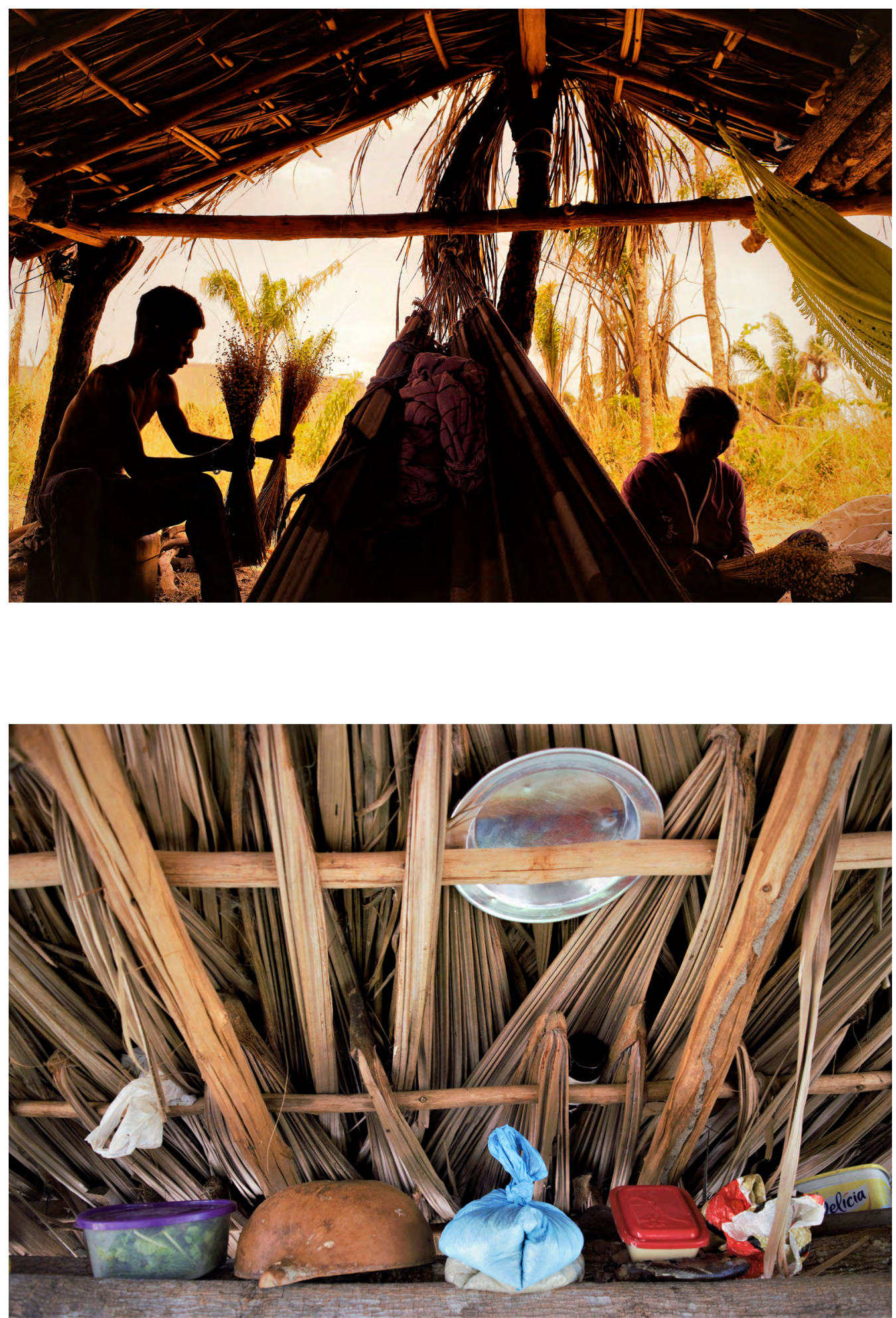


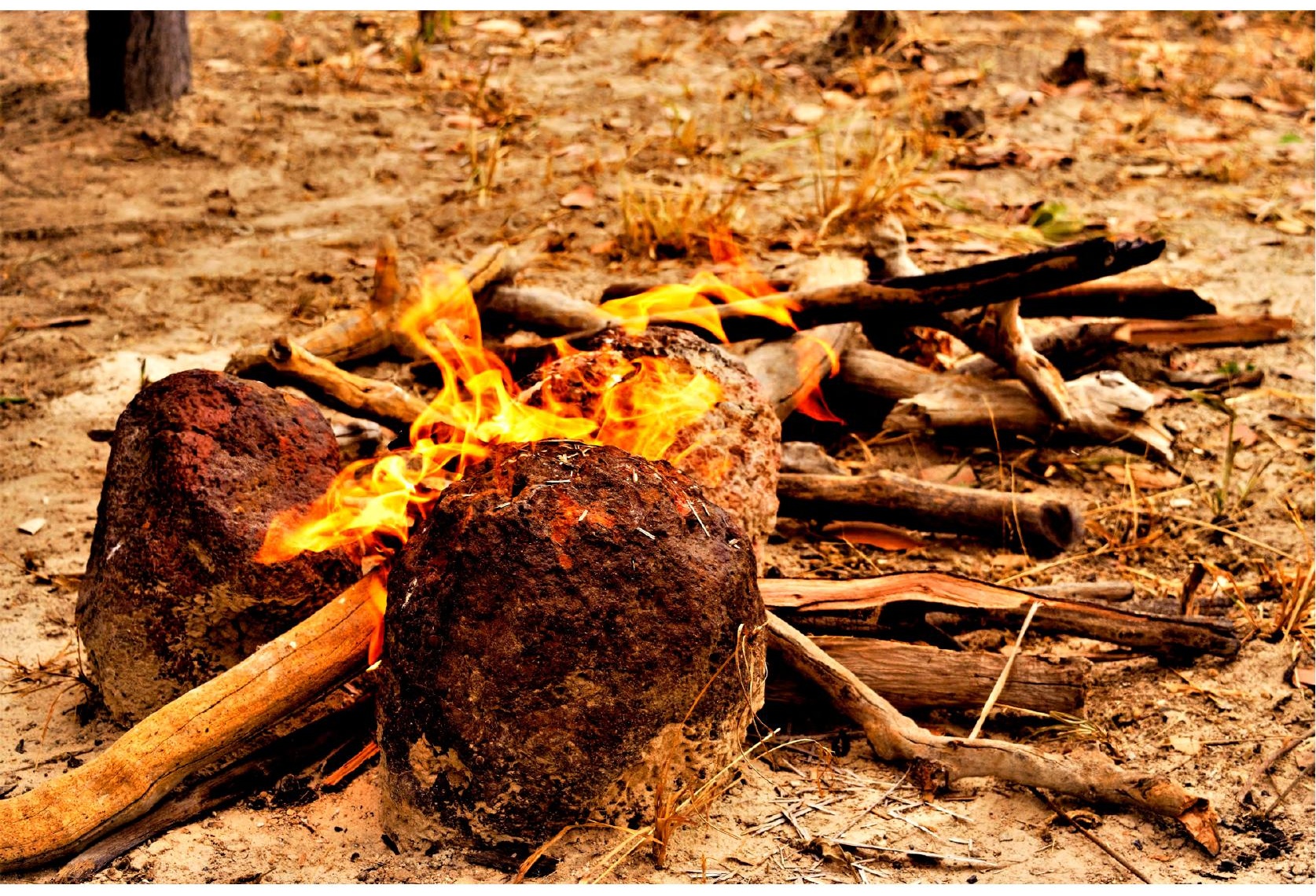

Além de local de descanso das pernas e trabalho com as mãos, é também na rancharia onde se desenrola a partilha de histórias sobre as luvizias (assombrações) e façanhas do povo de primeiro. Nesta habitação, coberta com palhas de buriti, sempre haverá pratos, talheres e condimentos de cozinha (principalmente sal e óleo) para serem usufruídos pelos que ali passarem para pernoitar. A trempa (acima) também é uma constante nestas instalações, pois apenas esta cuidadosa justaposição de três pedras consegue proteger o fogo doméstico do vento de gerais. 


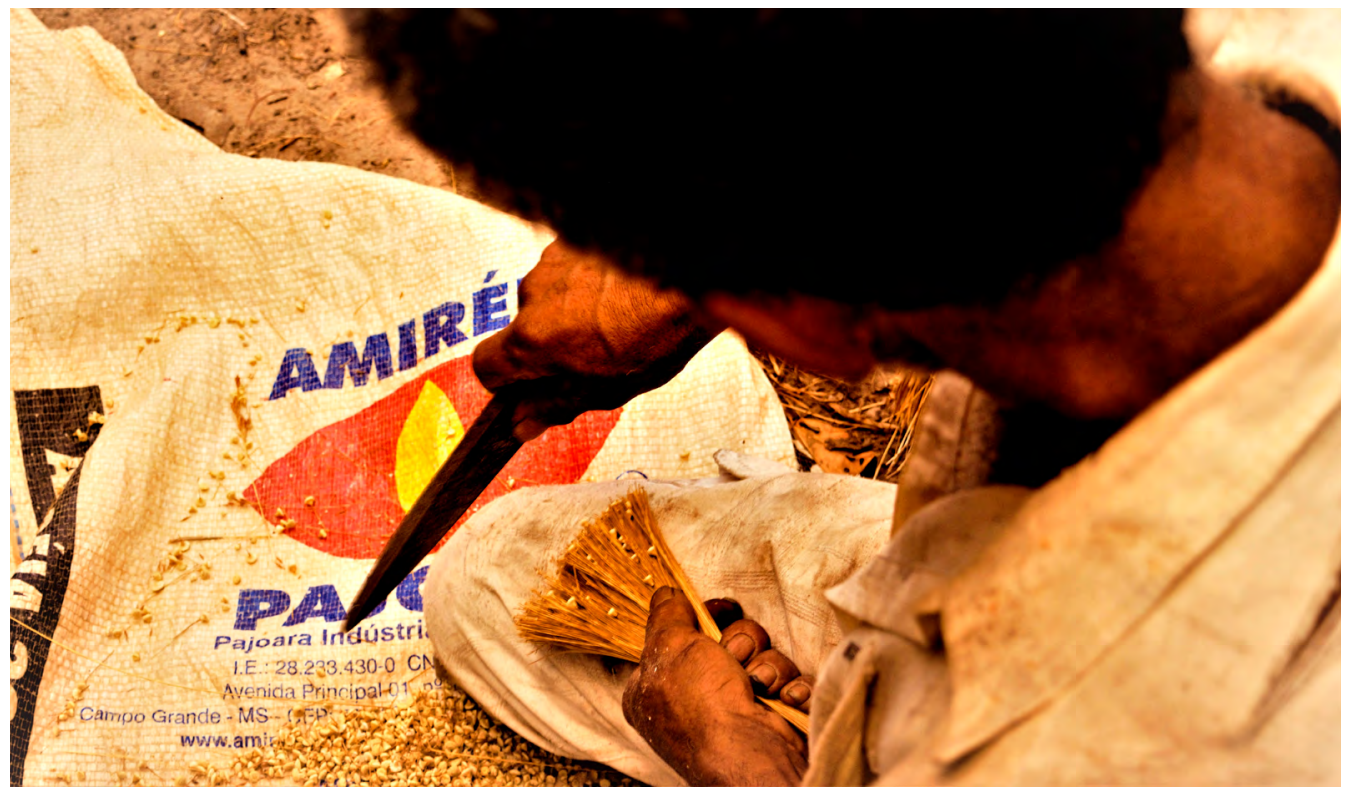

A raspagem é uma condicionante dos órgãos ambientais para a permissão de colheita. Os relatos de geralistas multados por não terem raspado as flores e as deixado no campo nutrem receios de maus encontros com agentes de fiscalização. Ainda que não fosse uma obrigação, Deni sabe que só assim o capim poderá renascer nas veredas. Chegando na rancharia, enquanto Iracema e Belarmina preparam o cozido, Deni e Dieison se dedicam a esta que é uma etapa bastante trabalhosa. Munidos de facas bem amoladas e apoiando os maços sobre uma das pernas, algumas horas são necessárias para finalizar a tarefa.

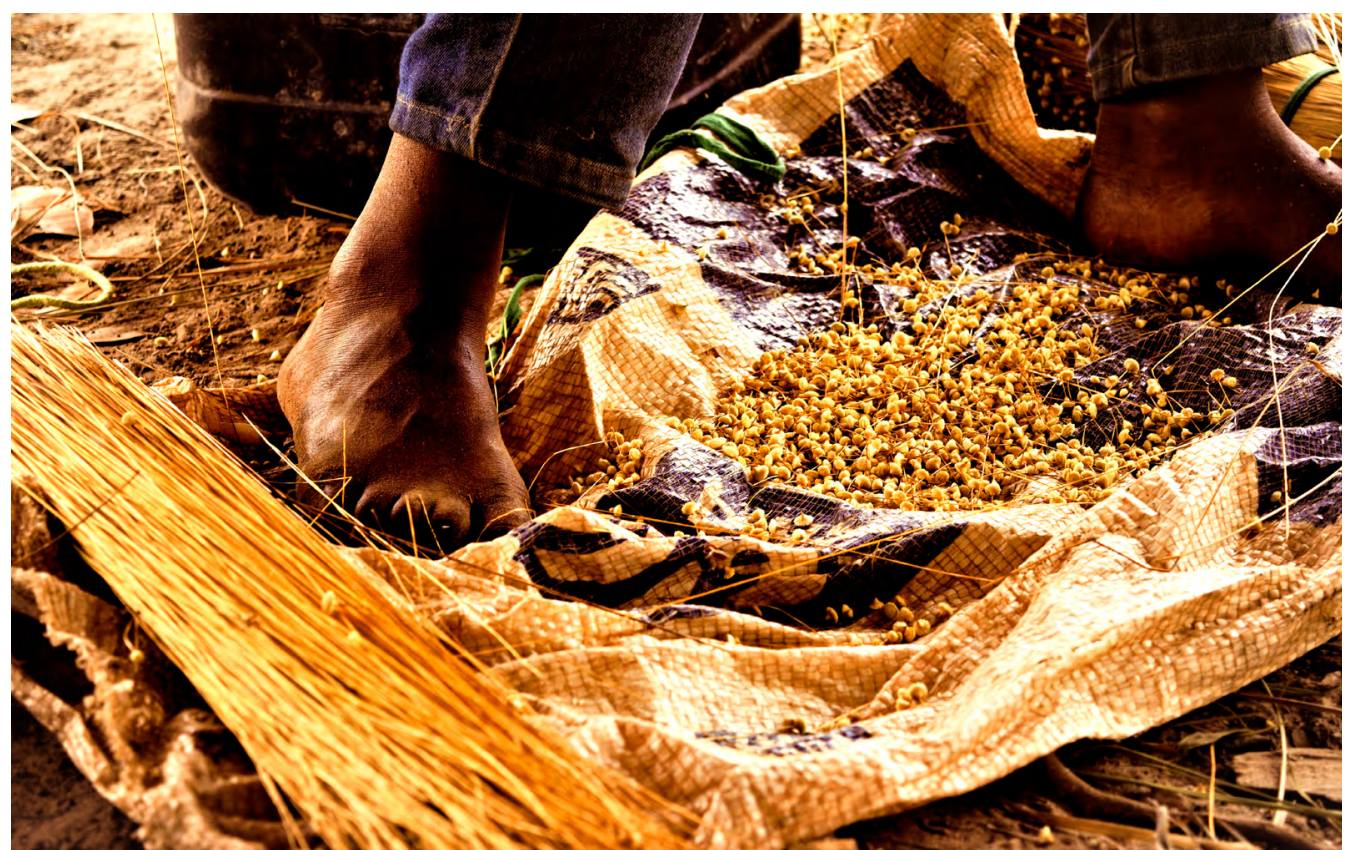




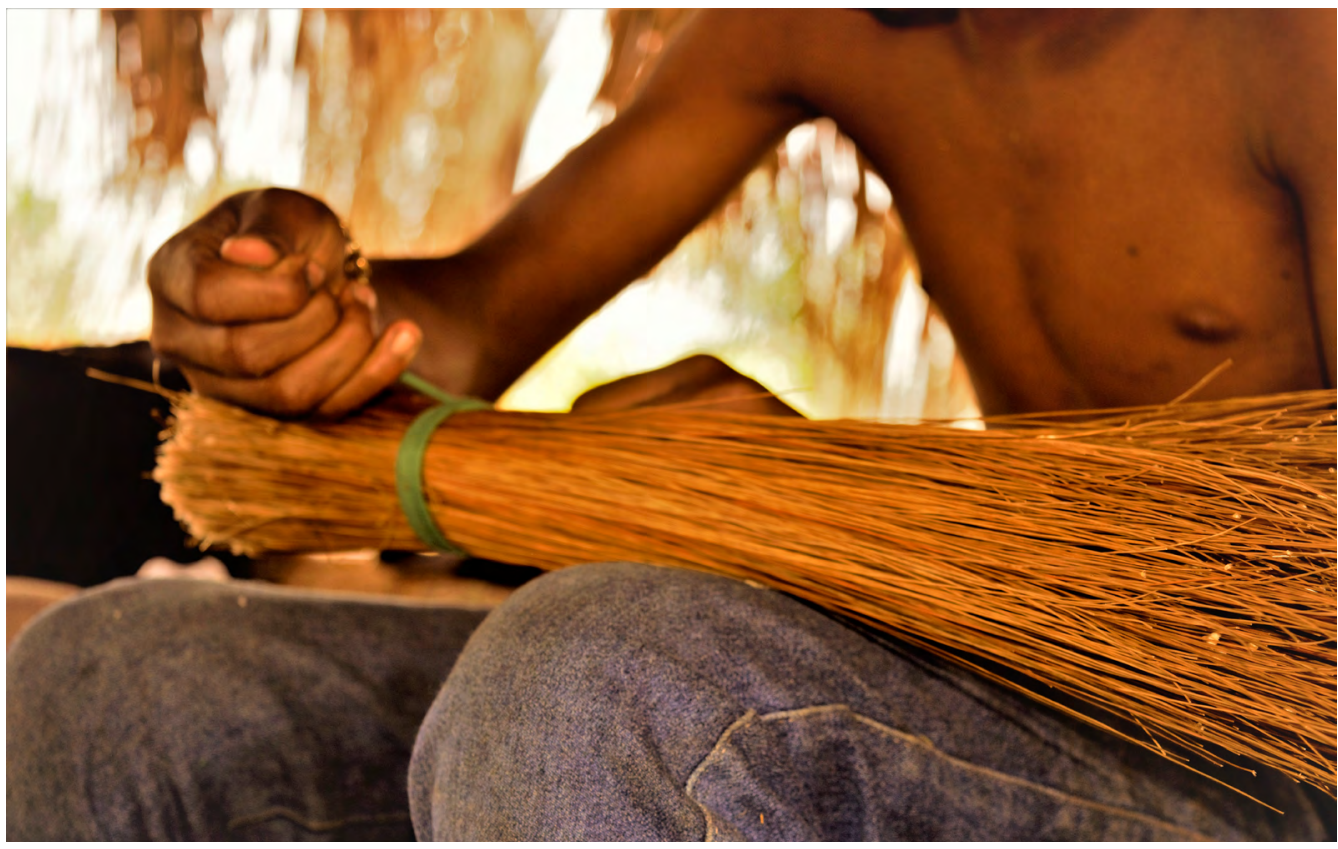

A separação dos maços visa deixá-los numa divisão que facilite a pesagem e a venda. Do grupo, apenas Belarmina, irmã de Deni, tem habilidade na costura do capim. Ela faz brincos, mandalas, e pequenos vasos, como um que ela me presentou. A maior parte desta colheita, entretanto, já estava reservada para um compadre. Outra parte seria vendida para a associação de artesões no valor de quarenta reais o quilo. O restante foi deixado em reserva para o período no qual não é permitido coletar (sobretudo de março a agosto), quando o preço tende a ser mais elevado.

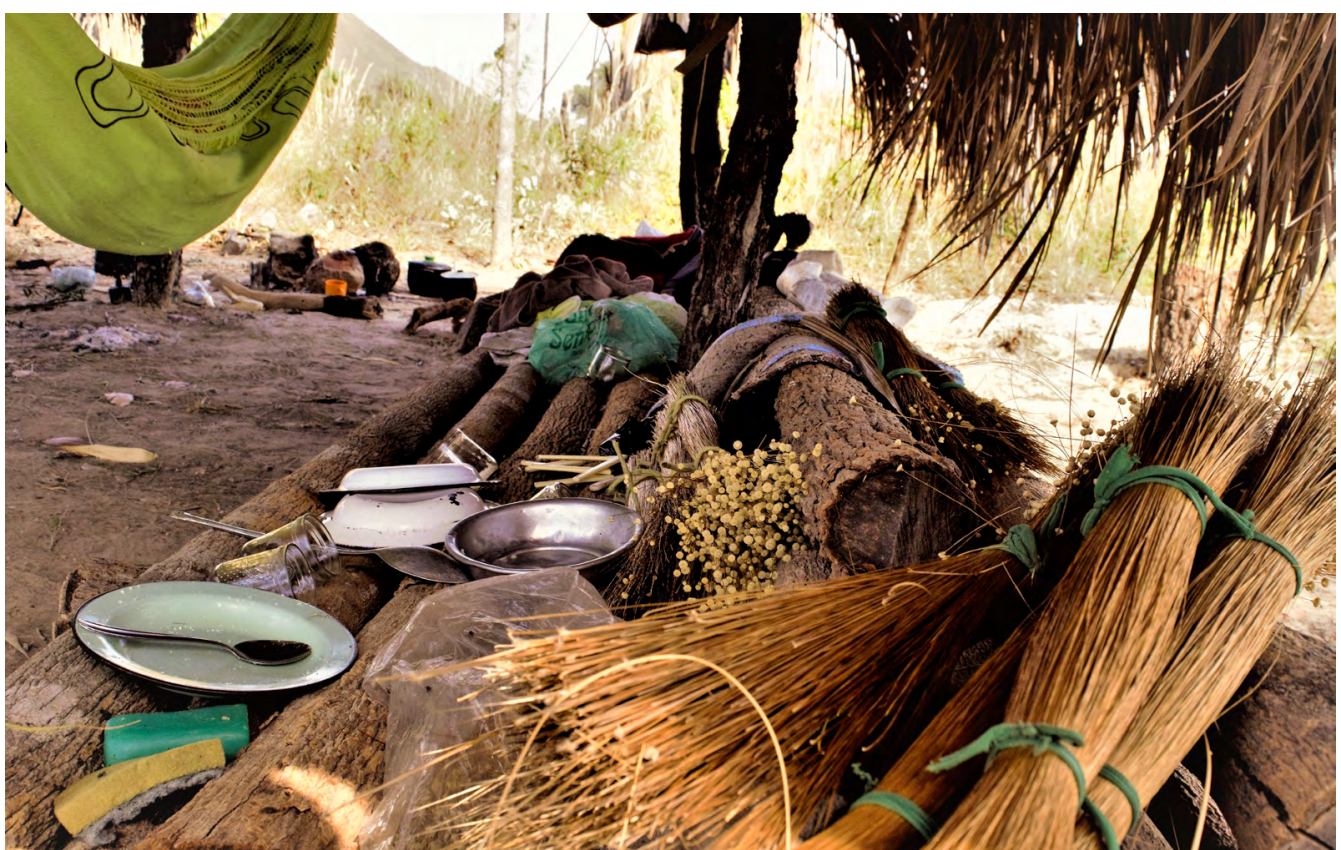


A venda se dá no peso. Para isso, Deni utiliza a balança jalapoeira. O aparelho, de mais de trinta anos, foi feito artesanalmente com um pedaço de pau louro, cuja madeira lisa, leve e uniforme é amarrada com arame e corda na extremidade. O movimento da argola provocado pelo peso do maço indicará o peso final de até 16 quilos. Nesta imagem, Deni está pesando um maço de 3,5 quilos, coletado por Dieison e vendido a um compadre.

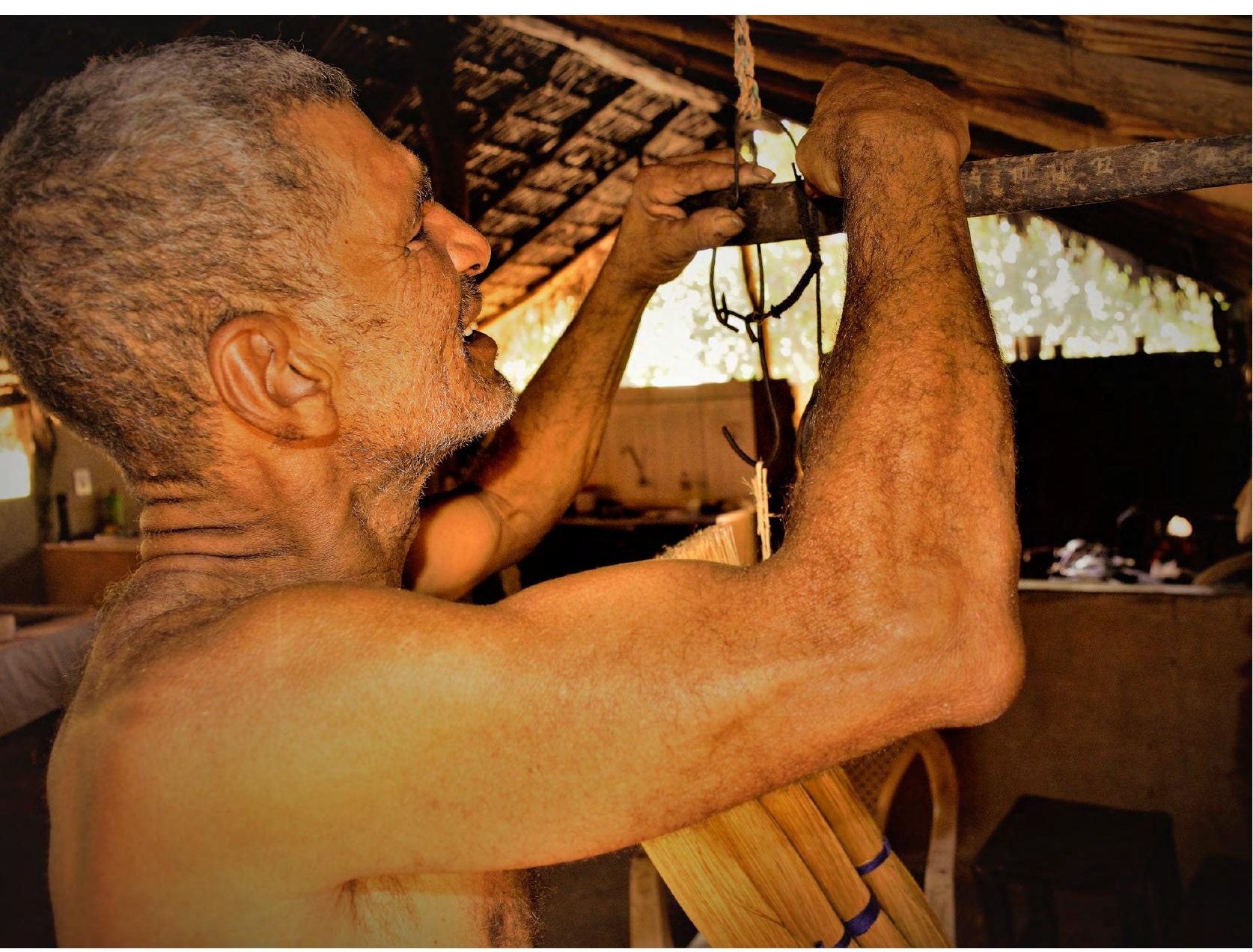

Recebido: 31/07/2018

Aprovado: 09/01/2019 
Guilherme Moura Fagundes é doutor em Antropologia Social pela Universidade de Brasília (UnB), com estágio sanduíche no Laboratoire d'Anthropologie Sociale (LAS - Collège de France/EHESS, Paris). Atua principalmente nas áreas de antropologia da técnica, antropologia da conservação e antropologia fílmica, com ênfase nos processos e nas políticas de manipulação da vida e dos viventes. ORCID: 0000-0003-2510-0465. Contato: guilhermefagundesantro@gmail.com 